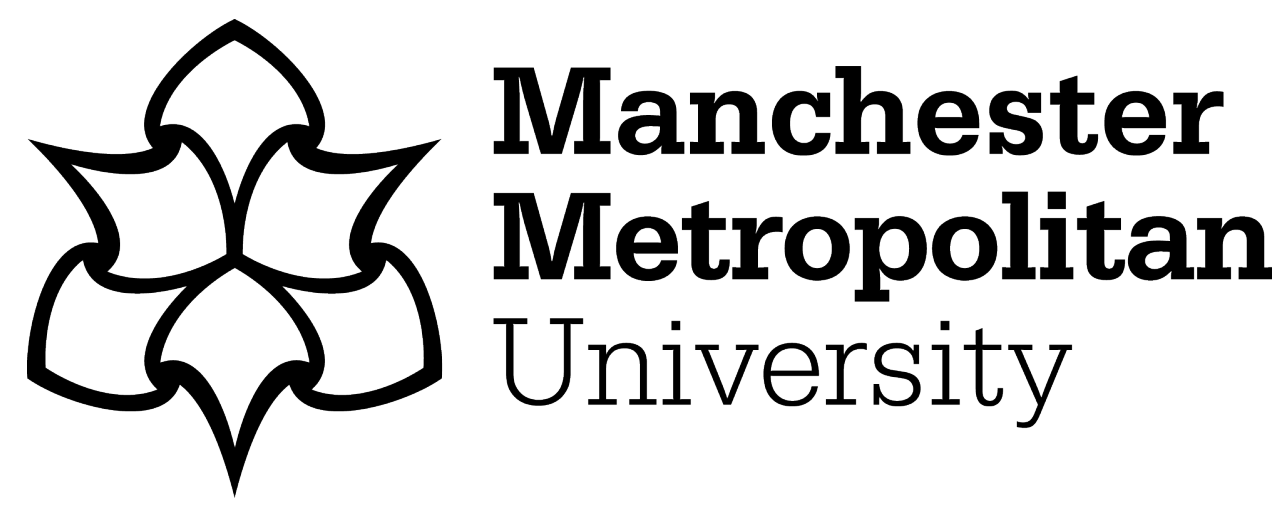

Lim, C ORCID logoORCID: https://orcid.org/0000-0003-2916-8221, Alavijeh, AS, Lauritzen, M, Kolodziej, J, Knights, S and Kjeanga, E (2015) Fuel cell durability enhancement with cerium oxide under combined chemical and mechanical membrane degradation. ECS Electrochemistry Letters, 4 (4). F29F31. ISSN 1099-0062

Downloaded from: https://e-space.mmu.ac.uk/625206/

Version: Published Version

Publisher: IOP

DOI: https://doi.org/10.1149/2.0081504eel

Usage rights: Creative Commons: Attribution-Noncommercial-No Derivative Works 4.0

Please cite the published version 


\title{
Fuel Cell Durability Enhancement with Cerium Oxide under Combined Chemical and Mechanical Membrane Degradation
}

\author{
C. Lim, ${ }^{\text {a,* }}$ A. Sadeghi Alavijeh,,${ }^{\text {a,* }}$ M. Lauritzen, ${ }^{\text {b,* }}$ J. Kolodziej, ${ }^{\text {b }}$ S. Knights, ${ }^{\text {b }}$ \\ and E. Kjeang $\mathbf{g}^{\mathrm{a}, *, \mathrm{z}}$
}

${ }^{a}$ School of Mechatronic Systems Engineering, Simon Fraser University, Surrey, British Columbia, Canada V3T0A3

${ }^{b}$ Ballard Power Systems, Burnaby, British Columbia, Canada V5J5J8

\begin{abstract}
$\mathrm{A} \mathrm{CeO}_{2}$ supported membrane electrode assembly (MEA) was fabricated by hot-pressing $\mathrm{CeO}_{2}$-coated electrodes and a PFSA ionomer membrane. Upon application of a combined chemical and mechanical accelerated stress test (AST), the $\mathrm{CeO}_{2}$ supported MEA showed six times longer lifetime and 40 times lower fluoride emission rate than a baseline MEA without cerium. The membrane in the $\mathrm{CeO}_{2}$ supported MEA effectively retained its original thickness and ductility despite the highly aggressive AST conditions. Most of the cerium applied on the anode migrated into the membrane and provided excellent mitigation of joint chemical and mechanical membrane degradation.

(C) The Author(s) 2015. Published by ECS. This is an open access article distributed under the terms of the Creative Commons Attribution Non-Commercial No Derivatives 4.0 License (CC BY-NC-ND, http://creativecommons.org/licenses/by-nc-nd/4.0/), which permits non-commercial reuse, distribution, and reproduction in any medium, provided the original work is not changed in any way and is properly cited. For permission for commercial reuse, please email: oa @electrochem.org. [DOI: 10.1149/2.0081504eel] All rights reserved.
\end{abstract}

Manuscript submitted January 13, 2015; revised manuscript received February 11, 2015. Published February 20, 2015.

In a polymer electrolyte fuel cell (PEFC), it is imminent to achieve extension of membrane lifetime for enhancing durability and hence cost-competitiveness of the PEFC system. Hydroxyl radicals, generated from hydrogen peroxide through the Fenton reaction, ${ }^{1}$ are known to be responsible for chemical degradation of perfluorosulfonic acid (PFSA) ionomer membranes used in PEFCs. ${ }^{2}$ One approach of mitigating the attack of hydroxyl radicals is to incorporate the $\mathrm{Ce}^{3+} / \mathrm{Ce}^{4+}$ redox system as a regenerative radical scavenger into the membrane $\mathrm{e}^{3-6}$ or catalyst layers ${ }^{7,8}$ which has been shown to reduce the fluoride emission rate during low humidity and open circuit voltage (OCV)-hold condition. Although uniform incorporation of $\mathrm{Ce}^{3+}$ by ion-exchanging of protons represented the most powerful scavenging effect on the attack of hydroxyl radicals, ${ }^{9,10}$ it can also introduce tradeoffs such as loss in high power performance due to the associated reduction in membrane conductivity. ${ }^{10}$ Moreover, cerium initially present inside a membrane was observed to migrate toward the catalyst layers during an accelerated stress test, where its mitigation function may not be preserved. ${ }^{8}$ The objective of the present work is to demonstrate the effectiveness of cerium under combined chemical and mechanical membrane degradation, representative of the actual membrane degradation mechanism during field operation of PEFCs.

Catalyzed gas diffusion electrodes (GDEs) were fabricated by coating a micro-porous layer onto a non-woven carbon paper gas diffusion layer (GDL) substrate, followed by coating a catalyst layer (CL) consisting of carbon-supported platinum catalyst and PFSA ionomer. A baseline MEA was prepared by hot-pressing a standard PFSA membrane with anode and cathode GDEs. $\mathrm{A} \mathrm{CeO}_{2}$-MEA was prepared in the same way with $\mathrm{CeO}_{2}$-coated anode and cathode GDEs. The $\mathrm{CeO}_{2}$-coated GDEs were fabricated by spray-coating a mixture solution consisting of a commercial cerium oxide powder (Alfa Aesar, 20-150 nm) and 5\% PFSA ionomer solution (Ion Power Inc., 1100 EW) on top of the anode and cathode GDEs. The $\mathrm{CeO}_{2}$ loading of the anode was controlled to be higher than for the cathode. The total loading of $\mathrm{CeO}_{2}$ was about $7 \mathrm{~mol} \%$ of the total number of sulfonic acid sites in the membrane.

A stack consisting of five MEAs having active area of $45 \mathrm{~cm}^{2}$ per cell was subjected to a cyclic open circuit voltage (COCV) accelerated stress test (AST) protocol, ${ }^{11-13}$ designed to induce combined chemical and mechanical membrane degradation. Prior to applying the COCVAST procedure, the stack was subjected to a beginning of life (BOL) conditioning procedure for $12 \mathrm{hrs}$. Fig. 1a represents the obtained trends in open circuit voltage and high frequency (HF) impedance as a function of AST operation time for a baseline $\mathrm{MEA}$ and $\mathrm{a} \mathrm{CeO}_{2}-\mathrm{MEA}$.

*Electrochemical Society Active Member.

${ }^{\text {zE} E-m a i l: ~ e k j e a n g @ s f u . c a ~}$
Whereas the AST lifetime of the baseline MEA was determined to be 186 hours based on a threshold $\mathrm{H}_{2}$ leak rate, ${ }^{13}$ the lifetime of the $\mathrm{CeO}_{2}$ MEA was remarkably extended to 1,244 hours, demonstrating a sixfold enhancement in lifetime. Fig. 1b shows cumulative fluoride loss profiles concurrently obtained during the AST from the baseline and the $\mathrm{CeO}_{2}$-MEA. Whereas the cumulative fluoride loss of the baseline MEA reached $82 \mu \mathrm{mol} \mathrm{F} \cdot \mathrm{cm}^{-2}$ at 186 hours, that of the $\mathrm{CeO}_{2}-\mathrm{MEA}$ was only $2 \mu \mathrm{mol} \mathrm{F} \cdot \mathrm{cm}^{-2}$ at the same number of hours and reached $9 \mu \mathrm{mol} \mathrm{F} \cdot \mathrm{cm}^{-2}$ at the EOL of 1,244 hours. Correspondingly, whereas the membrane thickness of the baseline MEA at EOL was determined by scanning electron microscopy (SEM) to be $52 \%$ of that at BOL, the membrane thickness of the $\mathrm{CeO}_{2}$-MEA at EOL was about $90 \%$ of that at BOL. It is known that the $\mathrm{Ce}^{3+}$ ion scavenges the hydroxyl radical by reducing it to water and $\mathrm{Ce}^{4+}$, and is regenerated from $\mathrm{Ce}^{4+}$ by reacting with hydrogen peroxide or hydroperoxyl radical. ${ }^{9}$ The decrease in hydroxyl radical concentration inside the membrane might reduce the radical attack toward the polymer chains, resulting in reduced FER in the $\mathrm{CeO}_{2}$ supported MEA as shown in Fig. 1b. It is emphasized that the chemical-mitigated $\mathrm{CeO}_{2}$-MEA failed four times earlier than the FER-predicted lifetime of 7,630 hours. Considering that the $\mathrm{CeO}_{2}$-MEA was exposed to more hydration cycles of the AST during the extended lifetime, it is believed that the $\mathrm{CeO}_{2}$-MEA must have accumulated more mechanical fatigue damage than the baseline MEA. In fact, from postmortem failure analysis by SEM, the $\mathrm{CeO}_{2}$ MEA revealed about $25 \mu \mathrm{m}$ wide pinholes with higher population, leading to progressive increase of hydrogen leak rate, than the baseline MEA having $100 \mu \mathrm{m}$ wide pinholes leading to sudden increase of hydrogen leak rate. It was reported that the MEA, which experienced more mechanical fatigue damage of hygrothermal cycling, exhibited formation of gas-leak initiating pinholes at less membrane thinning of chemical degradation. ${ }^{14}$

In practical point of view, a mitigation strategy of membrane degradation should meet the practical need of high power performance. During the AST operation, the HF impedance of the $\mathrm{CeO}_{2}-\mathrm{MEA}$ was evaluated to be about $0.26 \Omega \cdot \mathrm{cm}^{2}$ which is 1.5 times higher than the baseline $\left(0.18 \Omega \cdot \mathrm{cm}^{2}\right)$ as shown in Fig. 1a. Polarization curves were measured intermittently during the COCV-AST on different MEAs. Fig. 2 shows the evolution of cell voltages at different applied current densities obtained from the polarization curves of the baseline and the $\mathrm{CeO}_{2}$-MEA. While the cell voltages of the $\mathrm{CeO}_{2}$-MEA at high current densities $\left(0.66\right.$ and $\left.1.38 \mathrm{~A} \cdot \mathrm{cm}^{-2}\right)$ were initially lower than those of the baseline MEA due to the higher ohmic resistance, the former eventually outperformed the latter at the onset of hydrogen leaks across the membrane. In our result, the addition of $\mathrm{CeO}_{2}$ on the anode and cathode CLs not only extended the membrane durability but also stabilized the high power MEA performance as a consequence 


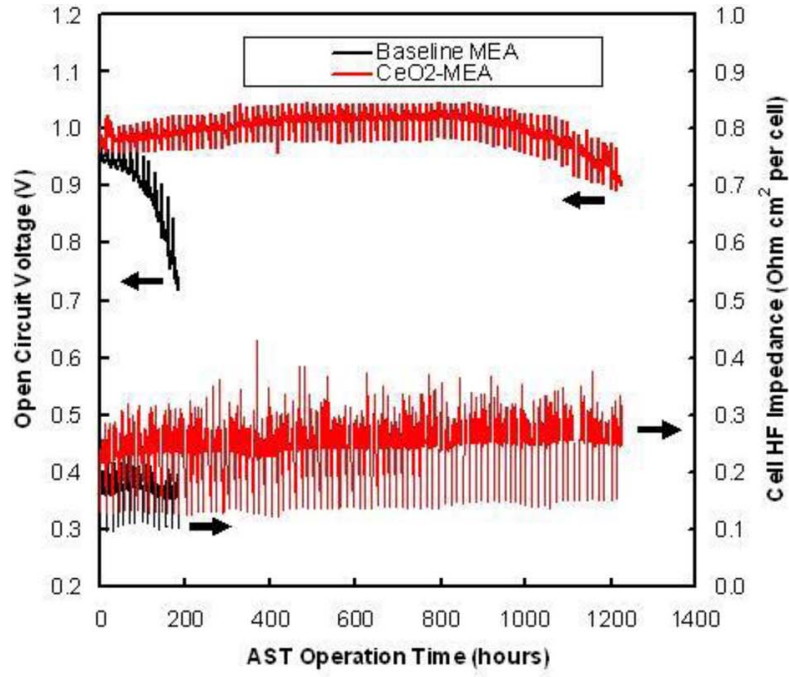

(a)

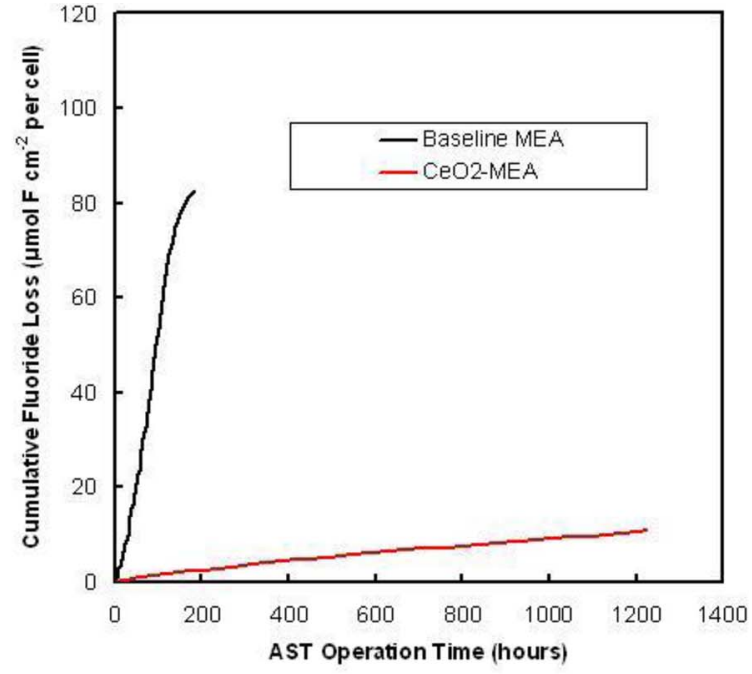

(b)

Figure 1. (a) Open circuit cell voltage and high frequency cell impedance; and (b) cumulative fluoride loss measured as a function of AST operation time.

of mitigating the membrane degradation and the performance losses induced by hydrogen leaks.

The mechanical properties of the membrane were previously shown to play an important role in the combined chemical and mechanical degradation process and were therefore evaluated at BOL and EOL in the present experiments using the same procedure. ${ }^{15-18}$ The obtained stress-strain curves of the baseline and $\mathrm{CeO}_{2}$-MEAs are depicted in Fig. 3 and the extracted properties are summarized in Table I. Both BOL MEAs exhibited similar tensile curves with ductile behavior and elongated to the maximum traction length of the instrument $(\sim 160 \%$ strain) without fracture. In contrast, the baseline MEA at EOL was fractured quickly at low levels of strain (2.3\%), indicating that the membrane experienced severe embrittlement as a result of the degradation process. ${ }^{13,18}$ However, the $\mathrm{CeO}_{2}$-MEA at EOL still exhibited good ductility up to the strain limit of the instrument, revealing that the $\mathrm{CeO}_{2}-\mathrm{MEA}$ retained much of the original ductility of the BOL membrane even after being exposed to a considerably longer period of AST operation. The elastic modulus of the baseline MEA was

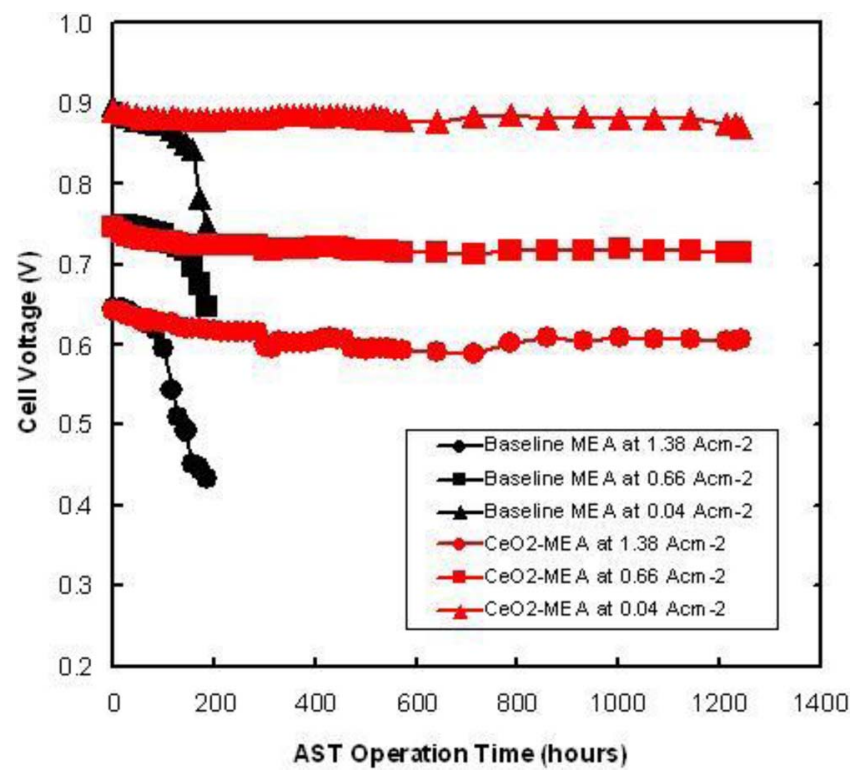

Figure 2. Decay in cell voltage at different applied current densities as a function of AST operation time. increased by $25 \%$ from BOL to EOL, indicating a stiffening effect, while that of the $\mathrm{CeO}_{2}$-MEA remained constant. Similarly, the ultimate tensile strength (UTS) of the baseline MEA diminished by $70 \%$ upon AST operation, while the UTS of the $\mathrm{CeO}_{2}$-MEA was effectively preserved. In addition to fluoride release and general thinning, the decay in the intrinsic mechanical properties represents evidence of changes in the polymer structure and morphology under the AST conditions. On the other hand, the preserved mechanical properties of the $\mathrm{CeO}_{2}$-MEA at EOL demonstrates that the addition of $\mathrm{CeO}_{2}$ effectively mitigated the chemically induced degradation of the polymer while substantially preventing the loss in mechanical strength and ductility, otherwise known to be a precursor to mechanical failure under COCV-AST conditions. ${ }^{18}$

The distribution and concentration of cerium in the $\mathrm{CeO}_{2}$-MEAs were determined by neutron activation analysis (NAA). Fig. 4

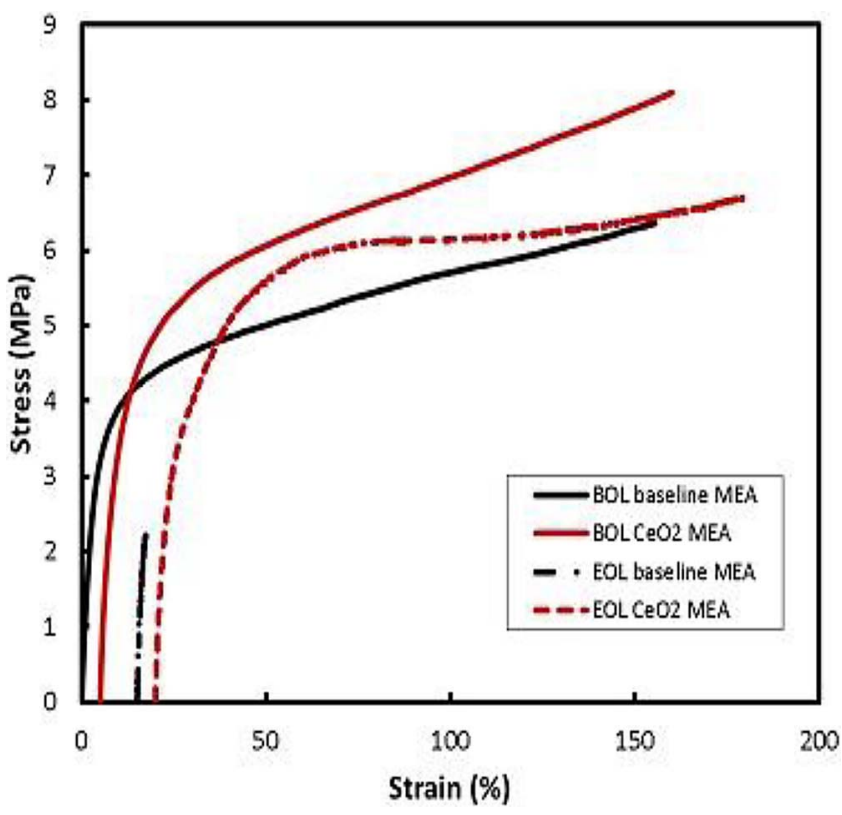

Figure 3. Tensile stress-strain curves measured at fuel cell conditions $\left(70^{\circ} \mathrm{C}\right.$, $90 \% \mathrm{RH})$ on the baseline and $\mathrm{CeO}_{2}$ supported catalyst coated membranes (CCMs) extracted from MEAs. For graphical clarity, the origins were in some cases shifted to higher strains (i.e., 5, 15, and 20\%). 
Table I. Mechanical properties of the baseline and $\mathrm{CeO}_{2}$ supported $\mathrm{CCMs}$ at the $\mathrm{BOL}$ and EOL stages obtained from the tensile stress-strain curves at $70^{\circ} \mathrm{C}$ and $90 \%$ RH (cf., Fig. 3).

Sample conditions

\begin{tabular}{|c|c|c|c|c|}
\hline \multirow{2}{*}{ Properties } & \multirow{2}{*}{\multicolumn{2}{|c|}{ Baseline CCM }} & & \\
\hline & & & \multicolumn{2}{|c|}{$\mathrm{CeO}_{2}-\mathrm{CCM}$} \\
\hline Elastic modulus (MPa) & $142( \pm 9)$ & $177( \pm 17)$ & $164( \pm 17)$ & $155( \pm 23)$ \\
\hline
\end{tabular}

illustrates the obtained results in the anode/cathode CLs and membranes at BOL, BOL-conditioned, and EOL stages. The BOL membrane already contained a substantial amount of cerium that presumably migrated from the electrodes during the hot-pressing procedure. After the BOL-conditioning treatment, cerium appeared to migrate further from the anode into the membrane. At EOL, the membrane was determined to have a higher cerium concentration than the anode $\mathrm{CL}$, from which most of the cerium was dissolved. Meanwhile, some of the cerium initially contained within the MEA was lost by wash-out from both sides of the MEA during AST operation.

The cerium migration behavior in the MEA was previously evidenced in the literature. ${ }^{8}$ Whether cerium was positioned only in the membrane as an ion-exchanged form (DuPont XL membrane) or only in the cathode $\mathrm{CL}$ in the form of cerium oxide, the cerium profile across the MEA shown by X-ray fluorescence (XRF) spectroscopy revealed that the ultimate location of cerium after fuel cell operation was in the anode and cathode catalyst layers, leaving little cerium in the membrane. On the contrary, our result in Fig. 4 suggests that most of the cerium originally situated at the anode was dissolved and migrated into the membrane, and resided inside the membrane during the COCV-AST operation. Considering that the HF cell impedance of the $\mathrm{CeO}_{2}$ supported MEA, mainly representing the ohmic resistance of the membrane, increased with AST time as shown in Fig. 1a, the cerium seemed to migrate into the membrane in the form of cerium ions, partially replacing $\mathrm{H}^{+}$sites in the membrane by cation exchange and therefore decreasing the proton conductivity of the membrane. This trend in HF impedance is qualitatively in agreement with the cerium concentration in the membrane obtained by NAA. The cerium is determined to occupy $3.0 \mathrm{~mol} \%$ of the total number of sulfonic

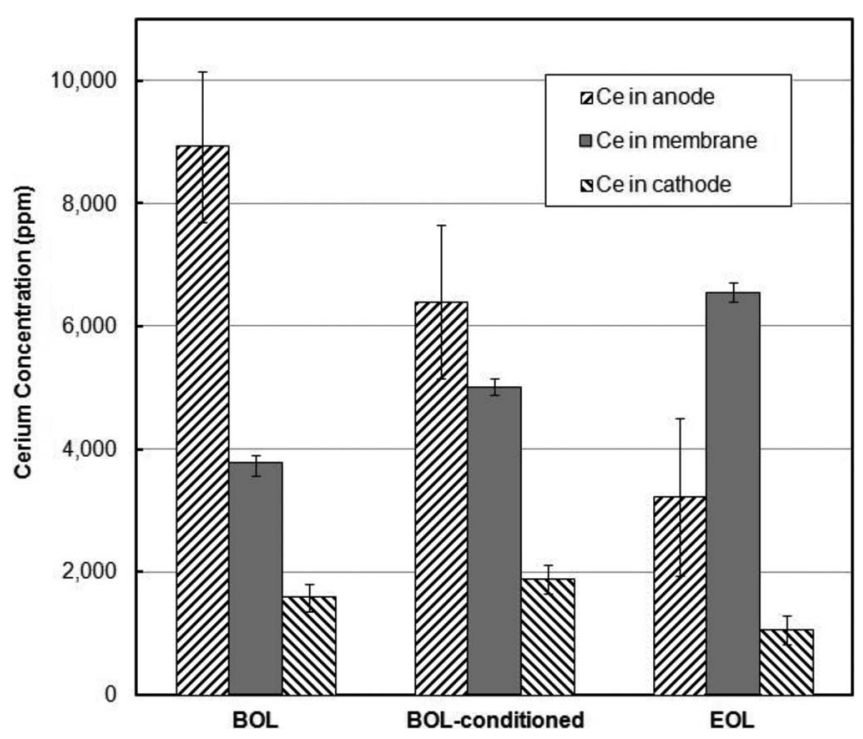

Figure 4. Cerium concentrations determined by Neutron Activation Analysis (NAA) at anode catalyst layer, membrane, and cathode catalyst layer from BOL, BOL-conditioned, and EOL MEAs where $\mathrm{CeO}_{2}$ was initially coated on the electrodes. acid sites in the membrane at BOL state and migrated further into the membrane up to $5.1 \mathrm{~mol} \%$ at EOL state. Albeit the present result is promising, the stability of cerium in the MEA is subject to further research.

In summary, upon subjecting to a combined chemical and mechanical accelerated stress test, the $\mathrm{CeO}_{2}$ supported MEA showed six times longer lifetime and 40 times lower fluoride emission rate than a baseline MEA without cerium. The EOL membrane in the $\mathrm{CeO}_{2}$ supported MEA was observed to retain its thickness and ductility comparable to the BOL membrane. The $\mathrm{CeO}_{2}$ applied on the electrodes is believed to be dissolved into $\mathrm{Ce}$ ions which migrate into the membrane and reduce the rate of chemical degradation through hydroxyl radical scavenging. This action was shown to be effective under combined chemical and mechanical degradation conditions, which suggests that mechanical failures can be delayed by mitigation of chemical degradation and avoidance of the associated loss in mechanical strength.

\section{Acknowledgments}

Funding for this research provided by Automotive Partnership Canada (APC), Natural Sciences and Engineering Research Council of Canada (NSERC), and Ballard Power Systems is gratefully acknowledged. Ballard Power Systems is also acknowledged for providing access to experimental facilities and technical support. The authors thank F. Van Hove and T. Hung for assisting with testing and characterization

\section{References}

1. F. Haber and J. Weiss, Proc. R. Soc. London. Ser. A, 134, 332 (1934)

2. K. H. Wong and E. Kjeang, J. Electrochem. Soc., 161, F823 (2014).

3. P. Trogadas, J. Parrondo, and V. Ramani, Electrochem. Solid State Lett., 11, B113 (2008).

4. S. Xiao, H. Zhang, C. Bi, Y. Zhang, Y. Zhang, H. Dai, Z. Mai, and X. Li, J. Power Sources, 195, 5305 (2010).

5. B. P. Pearman, N. Mohajeri, D. K. Slattery, M. D. Hampton, S. Seal, and D. A. Cullen, Polym. Degrad. Stab., 98, 1766 (2013).

6. B. P. Pearman, N. Mohajeri, R. P. Brooker, M. P. Rodgers, D. K. Slattery, M. D. Hampton, D. A. Cullen, and S. Seal, J. Power Sources, 225, 75 (2013).

7. L. Wang, S. G. Advani, and A. K. Prasad, Electrochim. Acta, 109, 775 (2013).

8. S. M. Stewart, D. Spernjak, R. Borup, A. Datye, and F. Garzon, ECS Electrochem. Lett., 3(4), F19 (2014).

9. E. Endoh, ECS Trans., 25(35), 293 (2010)

10. F. D. Coms, H. Liu, and J. E. Owejan, ECS Trans., 16(2), 1735 (2008).

11. E. Kjeang, C. Lim, L. Ghassemzadeh, N. Macauley, A. Tavassoli, R. Khorasany, M. A. Goulet, J. To, S. Diprose, M. Cruickshank, F. Feng, G. Wang, N. Rajapakse, S. Holdcroft, M. Lauritzen, J. Kolodziej, M. Watson, and S. Knights, in 63rd Annual Meeting of the International Society of Electrochemistry, Prague (2012).

12. N. Macauley, L. Ghassemzadeh, C. Lim, M. Watson, J. Kolodziej, M. Lauritzen, S. Holdcroft, and E. Kjeang, ECS Electrochem. Lett., 2 (4), F33 (2013)

13. C. Lim, L. Ghassemzadeh, F. V. Hove, M. Lauritzen, J. Kolodziej, G. G. Wang, S. Holdcroft, and E. Kjeang, J. Power Sources, 257, 102 (2014).

14. Y. H. Lai and G. W. Fly, J. Power Sources, 274, 1162 (2015).

15. M.-A. Goulet, R. M. H. Khorasany, C. De Torres, M. Lauritzen, E. Kjeang, G. G. Wang, and N. Rajapakse, J. Power Sources, 234, 38 (2013).

16. N. Macauley, A. Sadeghi Alavijeh, M. Watson, J. Kolodziej, S. Knights, G. G. Wang, and E. Kjeang, J. Electrochem. Soc., 162(1), F98 (2015).

17. M.-A. Goulet, S. Arbour, M. Lauritzen, and E. Kjeang, J. Power Sources, 274, 94 (2015).

18. A. Sadeghi Alavijeh, M.-A. Goulet, R. M. H. Khorasany, J. Ghataurah, C. Lim, M. Lauritzen, E. Kjeang, G. G. Wang, and N. Rajapakse, Fuel Cells, 15, 204 (2015). 